\title{
INERTIA THEOREMS BASED ON OPERATOR LYAPUNOV EQUATIONS
}

\author{
LeONid LeRer, IgOR Margulis AND André C. M. RAN
}

\begin{abstract}
The well-known Carlson-Schneider inertia theorem for finite matrices, satisfying the Lyapunov equation with a semi-definite right-hand side, is extended to linear operators acting on an infinite dimensional Hilbert space. The proofs use extensively the theory of linear operators acting on indefinite inner product spaces. An application to stability problems of semigroups is also presented.
\end{abstract}

Mathematics subject classification (2000): 47A62, 47B06, 47B50, 47D60, 47N70, 93A99, 15A24. Key words and phrases: Spectrum localization, Lyapunov equation, inertia theorems, bisemigroup.

\section{REFERENCES}

[1] T. YA. AzIZOV AND I. S. IoKHVIDOv, Linear operators in spaces with an indefinite metric, Pure and Applied Mathematics (New York), John Wiley \& Sons Ltd., Chichester, 1989.

[2] H. BARTL, I. GOHBERG AND M. A. KAASHOEK, Wiener-Hopf factorization, inverse Fourier transforms and exponentially dichotomous operators, J. Funct. Anal., 68, 1 (1986) 1-42.

[3] J. W. BunCE, Inertia and controllability in infinite dimensions, J. Math. Anal. Appl., 129, 2 (1988) $569-580$.

[4] B. E. CAIN, An inertia theory for operators on a Hilbert space, J. Math. Anal. Appl., Journal of Mathematical Analysis and Applications, 41 (1973) 97-114.

[5] D. H. CARLSON AND H. SCHNEIDER, Inertia theorems for matrices: the semi-definite case, Bull, Amer. Math. Soc., 68 (1962) 479-483.

[6] C. T. CHEN, A generalization of the inertia theorem, SIAM J. Appl. Math., 25 (1973) 158-161.

[7] R. F. CURTAIN AND H. ZWART, An introduction to infinite-dimensional linear systems theory, Texts in Applied Mathematics, Vol. 21, Springer-Verlag, New York, 1995.

[8] JU. L. DALEC' KII AND M. G. KREĬN, Stability of solutions of differential equations in Banach space, American Mathematical Society, Providence, R.I., 1974.

[9] K.-J. ENGEL AND R. NAGEL, One-parameter semigroups for linear evolution equations, Graduate Texts in Mathematics, 194, (With contributions by S. Brendle, M. Campiti, T. Hahn, G. Metafune, G. Nickel, D. Pallara, C. Perazzoli, A. Rhandi, S. Romanelli and R. Schnaubelt), Springer-Verlag, New York, 2000.

[10] I. GOHBERG, P. LANCASTER AND L. RODMAN, Indefinite linear algebra and applications, Birkhäuser Verlag, Basel, 2005.

[11] Israel Gohberg, Seymour Goldberg and Marinus A. KaAshoek, Classes of linear operators. Vol. I, Operator Theory: Advances and Applications, Vol. 49, Birkhäuser Verlag, Basel, 1990.

[12] I. S. IOHVIDOV, AND M. G. KREĬN AND H. LANGER, Introduction to the spectral theory of operators in spaces with an indefinite metric, Mathematical Research, 9, Akademie-Verlag, Berlin, 1982.

[13] M. G. KREINN, Some new studies in the theory of perturbations of self-adjoint operators, First Math. Summer School, Part I (Russian), p. 103-187, Izdat. "Naukova Dumka”, Kiev, 1964.

[14] P. Lancaster And M. Tismentetsky, The theory of matrices, Computer Science and Applied Mathematics, Academic Press Inc., Orlando, FL, 1985.

[15] L. LERER AND L. RODMAN, Inertia theorems for Hilbert space operators based on Lyapunov and Stein equations, Math. Nachr., 198 (1999) 131-148. 
[16] A. OSTROWSKI AND H. SCHNEIDER, Some theorems on the inertia of general matrices, J. Math. Anal. Appl., 4 (1962) 72-84.

[17] A. J. SASANE AND R. F. CURTAIN, Inertia theorems for operator Lyapunov inequalities, Systems Control Lett., 43, 2 (2001) 127-132.

[18] J. SNYDERS AND M. ZAKAI, On nonnegative solutions of the equation $A D+D A^{\prime}=-C$, SIAM J. Appl. Math., 18 (1970) 704-714.

[19] H. STETKAER, On positive semidefinite solutions of the operator Lyapunov equation, J. Math. Anal. Appl., 69, 1 (1979) 153-170.

[20] O. TAUSSKY, A generalization of a theorem of Lyapunov, J. Soc. Indust. Appl. Math., 9 (1961) 640-643.

[21] D. Temme, Dissipative Operators in Indefinite Scalar Product Spaces, Vrije University of Amsterdam, 1996.

[22] H. K. WIMMER, Inertia theorems for matrices, controllability, and linear vibrations, Linear Algebra and Appl., 8 (1974) 337-343. 